\title{
A psicanálise nos primeiros tempos da Rússia Soviética
}

Psychoanalysis in the Early Days

of Soviet Russia

\section{Georgina Faneco Maniakas \\ Universidade Federal de São Carlos [uFscar] \\ Departamento de Psicologia}

\section{RESUMO}

O objetivo deste artigo é fazer uma breve exposição sobre a trajetória da psicanálise nos primeiros anos da Rússia soviética. Entre as práticas que tornaram a psicanálise acessível à classe trabalhadora, concentraremos nossa apresentação na experiência pioneira da "Casa das Crianças" (Detski Dom) de Moscou, primeira escola de educação infantil embasada em princípios psicanalíticos. Documentada por sua fundadora, Vera Schmidt, a escola funcionou entre I92I e I925, abrigando 30 crianças com idade entre I e 5 anos. Assim como a escola, nos anos que se seguiram à morte de Lênin e ao exílio de Trotsky as demais instituições psicanalíticas sucumbiram à censura ideológica. Em 1936, a repressão stalinista baniu oficialmente a psicanálise da União Soviética, interrompendo um processo que modificou a prática da psicanálise e ampliou o alcance cultural e social das ideias de Freud. Entretanto, o interesse pelo inconsciente se manteve, e no final dos anos 80 a psicanálise foi retomada na Rússia.

\section{PALAVRAS-CHAVE}

Psicanálise; Rússia Soviética;

Educação Infantil;

Casa das Crianças (Detski Dom);

Vera Schmidt.

\begin{abstract}
The purpose of this article is to give a brief account of the trajectory of psychoanalysis in the early years of Soviet Russia. Among the practices that have made psychoanalysis accessible to the working class, we will focus our presentation on the pioneering experience of Moscow's "House of Children" (Detski Dom), the first nursery school based on psychoanalytic principles. Documented by her founder, Vera Schmidt, the school worked from I92I to 1925, housing 30 children aged I to 5 years. Like the school, in the years following Lenin's death and Trotsky's exile others psychoanalytic institutions succumbed to ideological censorship. In 1936, Stalinist repression officially banned psychoanalysis from the Soviet Union, interrupting a process that modified the practice of psychoanalysis and broadened the cultural and social reach of Freud's ideas. However, interest in the unconscious remained, and in the late I980s psychoanalysis was resumed in Russia.
\end{abstract}

\section{KEY WORDS}

Psychoanalysis; Soviet Russia;

Childhood Education;

House of Children (Detski Dom);

Vera Schmidt. 
[...] a natureza do próprio homem está escondida nos recessos mais profundos e escuros do inconsciente [...].

Trotsky, 1925

\section{Introdução}

Após a revolução de 1917, a psicanálise entrou e se desenvolveu na Rússia Soviética ${ }^{\mathrm{I}}$ por meio da política educacional e científica de Lenin (I870-I924), e com o apoio de Trotsky (I879-1940). Lenin acreditava que sem uma drástica melhoria dos padróes culturais e um desenvolvimento acelerado da ciência, a realização do ideal comunista estava condenada. Por esse motivo, o líder soviético resistiu fortemente a todas as tentativas de combinar a abolição do capitalismo com a eliminação de suas conquistas culturais e científicas. Em 1920, dirigiu-se ao Congresso da Juventude com as seguintes palavras:

Mas se tentásseis tirar a conclusão de que se pode ser comunista sem ter assimilado os conhecimentos acumulados pela humanidade cometeríeis um enorme erro. Seria errado pensar que basta assimilar as palavras de ordem comunistas, as conclusôes da ciência comunista, sem assimilar a soma de conhecimentos de que o comunismo é conseqüência. O marxismo é um exemplo que mostra como o comunismo surgiu da soma dos conhecimentos humanos [...]. Sem a compreensão clara de que só com um conhecimento preciso da cultura criada por todo o desenvolvimento da humanidade, só com a sua reelaboração, se pode construir a cultura proletária, sem esta compreensão não realizaremos esta tarefa (Lenin, 20II [1920], pp. 368-369).

Essas consideraçôes foram diretrizes para todas as decisôes de Lenin relativas à sua política educacional. ${ }^{2}$ A Rússia e demais províncias do antigo império apresentavam um índice alarmante de analfabetismo, além de não possuírem energia elétrica e serem compostas por camponeses - o proletariado foi construído após a revoluçáo com a implantação e desenvolvimento das hidroelétricas e indústrias pesadas. Estimativas anteriores à revolução presumiam que a alfabetização dos habitantes de todo o território levaria centenas e até milhares de anos no caso das províncias mais afastadas da Ásia. ${ }^{3}$ Apesar de todas as dificuldades advindas da quase total carência de material físico e humano ${ }^{4}$, a política educacional de erradicação do analfabetismo implementada por

I Utilizamos o termo Rússia Soviética devido à consolidação da União Soviética se dar somente em I922.

2 Naquele mesmo ano foi criada a Comissão Extraordinária da Rússia para o Combate ao Analfabetismo.

3 Segundo Bittar e Ferreira Jr. (20I5, p. 438), uma estimativa realizada em 1906 pelo Boletim de Educação, publicação do Ministério da Educação czarista, a população total da parte europeia da Rússia só poderia ser alfabetizada em I20 anos; na Sibéria e no Cáucaso, em 430 anos; na Ásia Central, em 4.600 anos.

4 Detalhes sobre as tremendas dificuldades desse período da história da educação soviética podem ser encontrados no excelente artigo de Bittar e Ferreira Jr. (20II), A Educação na Rússia Soviética. 
Lenin iniciou um processo cujo resultado foi a alfabetização de 90 milhôes de pessoas. De acordo com Bittar e Ferreira Jr. (20II, p. 390), entre I923 e 1939, 50 milhóes de analfabetos e cerca de 40 milhóes de semi-analfabetos aprenderam a ler e a escrever.

Ainda segundo esses autores, a escola instituída pela revolução "não se caracterizou apenas pela combinação entre o ativismo pedagógico e os fundamentos da concepção marxista de educação", mas representou uma superação da velha escola, ao abolir "seu conteúdo religioso, nacionalista, e o método de ensino baseado na pura memorizaçáo dos conhecimentos" (Bittar e Ferreira Jr., 2015, p. 453).

Nesse contexto educacional revolucionário, uma experiência pedagógica sem precedentes deixou seu legado para a história da psicanálise. Trata-se da primeira escola infantil a funcionar com base em princípios psicanalíticos, a "Casa das Crianças" (Detski Dom) de Moscou. O relatório de tal experiência é retomado neste artigo, com base na leitura de seu texto original, publicado em 1924 pela Internationaler Psychoanalytischer Verlag, cotejado com sua única tradução em língua portuguesa, publicada por uma editora do Porto em 1975.

Devido ao longo período de repressão ao movimento psicanalítico — iniciado por Stalin em 1936, e mantido até o final da década de 80 - o material para pesquisa ainda é relativamente escasso, e o acesso às fontes primárias de informação é bastante limitado. Compreende-se, assim, que os autores consultados divirjam em relação a um ou outro detalhe histórico. Contudo, parece haver um acordo de que a experiência psicanalítica soviética demonstrou possibilidades inexploradas pelo Ocidente, no que se refere ao alcance social e cultural das ideias de Freud.

\section{A psicanálise no contexto soviético}

A psicanálise já havia se estabelecido como movimento na Rússia antes de 1917. Podemos dizer que a Rússia aceitou a noção de inconsciente antes de muitos países ocidentais. A primeira Sociedade Psicanalítica Russa foi criada em I9II por um pequeno grupo de acadêmicos. Entre eles, o médico Nikolai Osipov (I887-I934)', conhecido no ocidente por seu trabalho na história da psiquiatria, e Tatiana Rosenthal (I885-I92I), médica, que já militava ao lado dos bolcheviques em 1905. Formada pela Universidade de Zurique, Rosenthal se decide pela psiquiatria após a leitura de $A$ interpretação dos sonhos (1900), de Freud. Realiza sua formação em parte no Burghölzli e, em parte com Karl Abraham, em Berlim. Em igir publica um estudo inovador sobre o relacionamento da psicanálise com a literatura. No ano seguinte, na casa de Freud em Viena, participa das reunióes semanais da Sociedade Psicanalítica de Viena juntamente com sua conterrânea, Sabina Spielrein (I885-1942). ${ }^{6}$ Tatiana Rosenthal tinha como ideal fundir as ideias de Freud ao

5 Osipov estudou em Zurich, e deixou a Rússia por estar convencido de que os bolcheviques seriam hostis à psicanálise.

6 Sabina Spielrein, médica formada em Zurique, foi a primeira mulher a escrever uma dissertação de orientação psicanalítica, de acordo com o Psychoanalytikerinnen. Biografisches Lexikon (20I7). Em seu trabalho teórico "A Destruição como origem da Criação", antecipou ideias sobre a pulsão de 
marxismo. O próximo registro que se tem a seu respeito é encontrado no Comitê de Acolhimento a Lênin em sua volta à Rússia em abril de 1917.?

Considerada pelos bolcheviques como uma espécie de antídoto ao pensamento burguês, a psicanálise foi reconhecida oficialmente como ciência pelo governo soviético antes de qualquer outro país do mundo, e recebeu apoio estatal para a sua prática. Desse modo, no início da década de 1920, o movimento psicanalítico criava, na Rússia Soviética, um Instituto de Formaçáo, um Ambulatório e um Jardim de Infância experimental, que se tornaria conhecido como "Casa das Crianças" de Moscou.

Diferentemente do movimento ocidental, o movimento soviético acolheu membros provenientes de origens não-médicas — filosofia, estética, ciências naturais, educação (Brenner, 1999, p. 2). E, sobretudo, havia um grande interesse nas implicaçôes culturais e sociais das ideias de Freud. ${ }^{8}$

"Diante de nossos olhos, uma nova e original tendência na psicanálise está começando a se formar na Rússia, a qual, com a ajuda da teoria dos reflexos condicionados, tenta sintetizar a psicologia freudiana e o marxismo...”, diriam Vygotsky e Luria em I925.9

Vygotsky (I896-1934), que se tornaria a maior figura a emergir da psicologia soviética, juntamente ao seu grande colaborador, Alexander Luria (1902-1977), foram atraídos pela audácia teórica de Freud. Em um universo acadêmico "povoado por tantas mentes indecisas, pensamentos tímidos e hipóteses frágeis", no qual a "cautela e o seguir os passos de outras pessoas se tornaram atributos obrigatórios do trabalho acadêmico oficial, Freud fez sua estreia como revolucionário" (Vygotsky e Luria, I925, p. I0).

No primeiro parágrafo da Introdução à tradução russa de Além do Princípio do Prazer (1925), os psicólogos soviéticos escrevem:

Entre as grandes mentes de nossos tempos, Freud foi, provavelmente, um dos mais intrépidos. Uma qualidade como esta sempre foi considerada uma virtude mais adequada a um homem prático do que a um estudioso ou a um pensador. Coragem é necessária para um homem de ação, mas parece que uma quantidade infinitamente maior de ousadia é necessária para pensar (ibid.).

morte que Freud desenvolveria em Além do Princípio do Prazer (1920). Ao voltar à Rússia, em I923, foi colaboradora de Vera Schmidt na Casa das Crianças de Moscou. Apesar da proibição imposta pelo governo de Stalin, continuou praticando a psicanálise. Em 1942 foi morta com suas filhas em Rostov-sobre-o-Don, por um destacamento especial da ss Nazista.

7 Em 1920 Tatiana Rosenthal publica um artigo sobre o sofrimento e a criatividade de Dostoyevsky, no qual antecipa teses do posterior estudo de Freud sobre Dostoyevsky e o assassinato do pai. Dada a sua morte precoce, a segunda e terceira parte desse trabalho permanecem inéditas. Rosenthal iniciou um trabalho educacional nos moldes psicanalíticos em Petrogrado, antes mesmo da Casa das Crianças de Moscou, mas não há registros suficientes sobre essa experiência.

8 Brenner (I999, p. 3) apresenta em seu artigo alguns tópicos tratados nas reunióes iniciais da sociedade psicanalítica de Moscou: simbolismo nas estátuas dos deuses dos rios e dos vasos gregos, a melancolia nas pinturas de Albrecht Dürer. O instituto de Moscou foi provavelmente o único programa de treinamento psicanalítico no mundo a oferecer um seminário regular sobre psicologia da arte, apresentado pelo médico psiquiatra e psicanalista russo Ivan Ermakov (I875-1942), este particularmente interessado na interpretação psicanalítica do processo criativo.

9 Lev Vygostsky e Alexander Luria, I925, p. II. 
Tal audácia teórica refletiu-se também na prática, por meio de empreendimentos inovadores implementados pelo movimento psicanalítico soviético. O Ambulatório garantiu o acesso à análise a qualquer pessoa da população que desejasse ou fosse encaminhada para o tratamento de algum transtorno, objetivando ideias de Freud expostas em seu artigo "Caminhos da terapia psicanalítica" (I9I8-I919): a necessidade de oferecer terapia às massas, que não sofrem menos de neuroses do que os indivíduos de classes abastadas. Interessante notar que essas clínicas ambulatoriais iniciaram um processo que teve o potencial de mudar profundamente a própria psicanálise, tirá-la do setting convencional e leva-la às ruas, às fábricas, concretizando algumas das ideias de Wilhelm Reich (I897-1957), que desejava garantir a acessibilidade da terapia psicanalítica às classes trabalhadoras.

Mas o empreendimento ao qual dedicaremos esta exposição, por ter sido documentado por meio de um relatório publicado originalmente em 1924 pela Internationaler Psychoanalytischer Verlag, posteriormente retomado por Reich em 1929, e em I968 pelo Conselho Central dos Jardins de Infância Socialistas de Berlim, foi a experiência de um Jardim de Infância conhecido como "escola experimental" ou, literalmente do russo "Casa das Crianças" de Moscou (Detski Dom).

A Casa das Crianças de Moscou foi fundada em ig de agosto de I92I, com 30 crianças, variando de idades de I a 5 anos, provenientes de diferentes origens sociais: algumas eram de classe trabalhadora ou de famílias camponesas, alguns tinham pais que eram intelectuais ou ativistas partidários. ${ }^{10}$

Sua fundadora e idealizadora foi a educadora Vera Schmidt, nascida em Odessa em I889. Era filha de médicos e particularmente apegada à mãe, Elisaveta Yanitskaïa, que tratava crianças que sofriam de distúrbios neurológicos. Vera disse mais tarde que sua mãe exerceu uma influência determinante em sua escolha de carreira.

Em 1917, quando trabalhava em Kiev no Comitê de Suprimentos, desenvolveu uma paixão pelos livros de Freud, que leu nos originais por não haver ainda tradução para o russo.

Desde I9I3 estava casada com Otto Youlievitch Schmidt (I89I-I956), filho de camponeses de origem alemã e um entusiasta da Revolução de 1917, que compartilhava sua paixão pela psicanálise.

Otto Schmidt era astrônomo, matemático e geofísico, internacionalmente conhecido por suas expediçóes polares; foi membro da Academia Soviética de Ciências, editor-chefe da primeira edição da grande Enciclopédia Soviética, recebeu três Ordens de Lênin e também foi agraciado com o prêmio "Herói da União Soviética". Entre I92I e 1924 dirigiu a Editora Estatal (Casa de Publicação Estatal) e se tornou uma figura central na história da psicanálise na União Soviética, pois foi o responsável por publicar as obras de Freud em russo.

IO Segundo alguns autores, entre os quais Stanley (1996) e Brenner (1999), o filho de Stalin, Vasily, teria frequentado a Casa das Crianças de Moscou. Certamente uma ironia histórica, mas que demonstra a aceitação da psicanálise pela cultura soviética naquele período. 
Particularmente relevante para o nosso tema é o fato de Otto Schmidt tornar-se vice-presidente da Sociedade Psicanalítica Russa, tendo como presidente outra grande liderança do movimento psicanalítico soviético, Ivan Ermakov (I875-1942) ${ }^{\text {II }}$, além de dois dos membros fundadores da referida sociedade, os pedagogos e psicanalistas Stanislav Shatsky (I878-1934) e Pavel Blonsky (I884-I94I), ocuparem cargos ao lado da esposa de Lenin, Nadezhda Krupskaya (I869-1939), no Ministério da Educação Russo. Por meio dessa configuraçáo, Otto Schmidt favoreceu a subsistência das instituiçóes psicanalíticas durante os anos I92I a 1926.

No início de 1923, os Schmidts foram a Viena e conheceram Freud, com quem discutiram o projeto da "Casa das Crianças" de Moscou, a organização de um sistema educacional coletivo e outras atividades psicanalíticas na Rússia. Sob os auspícios de Freud, cuja simpatia ao movimento russo era óbvia, seu trabalho contribuiu para a Associação Psicanalítica Russa se tornar um membro associado da Associação Psicanalítica Internacional (IPA) em I924.

Podemos dizer que o ideal pedagógico preconizado por Vera Schmidt era a manifestação viva do espírito dos anos I920, que, depois da Revolução de Outubro, buscava concretizar o sonho de uma fusão possível entre a liberdade individual e a liberação social: uma verdadeira utopia pedagógica que combinava princípios freudianos ao ideal marxista.

\section{A Casa das Crianças de Moscou}

O Jardim de Infância "Casa das Crianças" de Moscou, localizado em um edifício Art Nouveau, estava ligado ao Instituto de Neuropsicologia de Moscou. A princípio foi financiado pelo Comissariado do Povo para a Instrução Pública. Sua organização era coletiva e estava baseada em princípios não autoritários. Como já mencionamos, atendia a um total de 30 crianças, com a faixa etária variando de i a 5 anos.

$\mathrm{Na}$ Casa das Crianças considerava-se essencial a realização de três tarefas: adaptação gradual das crianças às exigencias da realidade, controle das funçôes excretoras e a facilitação da sublimação das tendências pulsionais infantis (Schmidt, I924, p. I3; 1975, p. 22).

Vera Schmidt acreditava que seria possível promover a evolução harmoniosa do complexo desenvolvimento infantil se as fases de organização pré-genitais fossem levadas em consideração, uma vez que "cada passo ao longo desse caminho pode tornar-se o ponto de fixação de uma inibição no desenvolvimento que torne necessária a nossa intervenção e a nossa assistência (Schmidt, I924, p. IO; 1975, p. 20).

No artigo "Educação Psicanalítica na Rússia Soviética: Relatório sobre o Laboratório Casa das Crianças de Moscou", de I924 - ao qual nos referiremos a partir daqui como "Relatório", Schmidt expóe os princípios psicanalíticos que nortearam o seu trabalho. Tais princípios podem ser identificados como: I) o conceito de inconsciente; 2) os dois

II Ivan Ermakov, diretor da Clínica Psiquiátrica da Universidade de Moscou desde I9II, junto a Otto Schmidt traduziu e publicou as obras de Freud para o russo. Foi preso em 1940 e morreu dois anos depois (Van Der Veer, 20II, pp. 5I-53). 
princípios que governam a vida psíquica: princípio do prazer e princípio da realidade; 3) o reconhecimento e aceitação da sexualidade infantil; e 4) o conceito de transferência. Todos permeados pela ideia de determinismo psíquico.

A seguir, apresentaremos resumidamente as ideias da autora a respeito de cada um dos princípios, contidos na seção III do Relatório, denominada "Diretrizes psicanalíticas para o trabalho no laboratório Casa das Crianças".

I) O conceito do inconsciente. De acordo com Schmidt (1924, p. 9; 1975, pp. 19-20), a criança pequena está muito mais sujeita ao domínio do inconsciente do que o adulto; assim sendo, o educador deve ser capaz de reconhecer e interpretar as manifestaçóes do inconsciente infantil. Como a criança pequena encontra-se impotente diante das tendências que provêm de seu inconsciente, é tarefa do educador ajudá-la para que as possa dominar, sem condená-la. "Então, podemos ser bem sucedidos em fazê-la se conscientizar de sua própria força ao invés de sentir sua fraqueza” (Schmidt, 1924, p. 9; 1975, p. 19).

2) Os dois princípios que governam a vida psíquica: princípio do prazer e da realidade. Como a criança de tenra idade encontra-se totalmente sob o dominío do princípio do prazer, as suas aspiraçóes pulsionais estão voltadas à obtenção do prazer e à rejeição do desprazer, sem consideração alguma pelas exigências da realidade. É tarefa do educador facilitar sua compreensão progressiva das condições reais do mundo exterior, incitando-a "a ultrapassar o princípio do prazer e o substituir pelo princípio da realidade" (Schmidt, I924, p. 9; 1975, pp. 19-20).

3) Reconhecimento e aceitaçáo da sexualidade infantil. A abordagem dos educadores se expressava pela ausência de postura repressiva em relação a qualquer atividade infantil relacionada à expressão da sexualidade. Conseqüentemente, na escola eram permitidas operaçóes relacionadas à satisfaçóes parciais, como chupar o dedo, estar interessado em suas fezes, etc.

Apesar de não haver censura às manifestaçôes da sexualidade infantil, os educadores, no entanto, tinham como tarefa desviar a energia sexual para diferentes formas de sublimação: manipular argila, areia, água e, principalmente, não impor restriçóes às suas expressōes motoras, encorajando todos os tipos de tarefas criativas.

Nas palavras de Vera Schmidt (I924, pp. IO-II; 1975, pp. 20-2I):

As tendências sexuais conhecem os mais diversos destinos. Podem ser desviadas dos seus fins sexuais para fins socialmente superiores, não mais sexuais. Em psicanálise esse processo é chamado de sublimação. Mas as mesmas tendências podem igualmente ser submetidas à repressão. Desse modo, elas são impedidas de atingir o seu fim por um obstáculo psíquico, e são relegadas ao inconsciente; embora mantenham sua energia, que é desviada para outros caminhos em busca de satisfação.

Um exemplo é a abordagem da questão da masturbação. Schmidt distingue duas modalidades: a masturbação como um fenômeno normal, que tem sua origem na excitação dos órgãos genitais, e um segundo tipo, que ocorre como reação a frustrações. Nesse segun- 
do caso, as medidas educativas que promovem o restabelecimento do equilíbrio psíquico da criança contribuem para eliminar as causas da atividade masturbatória excessiva.

Segundo a educadora, é por meio da compreensão das manifestaçôes da sexualidade infantil que se torna possível facilitar a sublimação desenvovendo-se um comportamento pedagógico adequado, pois:

Se apenas uma pequena parcela das tendências pulsionais sofrer repressão e se uma grande parte da energia psíquica da criança ficar disponível para fins culturais e sociais, entáo o indivíduo também terá a oportunidade de um desenvolvimento muito mais rico e desinibido (Schmidt, I924, p. II; 1975, p. 2I).

4) Em relaçáo à transferência. Partindo do pressuposto de que esse fenômeno - em sua forma positiva ou negativa - ocorre em relação aos educadores, a educação deveria estimular uma transferência positiva da criança para com o educador, a fim de induzi-la a abandonar o princípio do prazer e gradualmente submeter-se ao princípio da realidade. Se, por outro lado, tiver sido gerada uma atitude negativa em relação ao educador, a criança também irá manter uma atitude hostil em relação às demandas sociais.

Para que o trabalho aconteça de forma satisfatória, por meio do desenvolvimento de uma atitude correta em relação às tendências pulsionais infantis, antes de mais nada é exigido um trabalho do educador sobre si próprio, ao qual Schmidt dedica um tópico especial de seu Relatório. Em suas palavras:

O educador deve, primeiramente, libertar-se dos preconceitos que a própria educação lhe legou através de um trabalho de análise sobre si mesmo, Deve tentar tornar conscientes as próprias tendências pulsionais reprimidas e reconhecer sua semelhança com as manifestaçóes que encontra nas crianças. Se, apesar dos esforços, não conseguir considerar as manifestações sexuais infantis sem repulsa ou desgosto, seria melhor renunciar ao trabalho de educador (Schmidt, I924, p. I8; 1975, p. 27).

Todos esses princípios são permeados pela noção de determinismo psíquico. Schmidt observa que, por não haver acaso no psiquismo, todas as manifestaçóes que poderiam parecer contingentes à primeira vista são determinadas por processos inconscientes. "Se considerarmos esse ponto de vista em nosso trabalho educacional, então o comportamento e as expressóes da criança nos darão muitos indícios a partir dos quais podemos desvendar as operaçóes que se desenrolam nas profundezas de seu inconsciente" (Schmidt, I924, p. II; 1975, p. 22).

Tais diretrizes, aqui brevemente expostas, não encerram a riqueza do Relatório, que subdivide-se em sete seçóes, cada qual trabalhando com temas específicos, todos permeados pela articulaçáo entre psicanálise e pedagogia. ${ }^{\text {I2 }}$

I2 O Relatório divide-se em sete tópicos, cada qual abordando um tema, a saber: o destino da Casa das Crianças, sua organização interna, as diretrizes psicanalíticas para o trabalho, os princípios pedagógicos gerais, as medidas educativas para cumprir tais exigências, o trabalho do educador sobre si mesmo, e observaçóes da vida na Casa das Crianças. Há, ainda, um Apêndice onde Schmidt narra alguns exemplos cotidianos que ilustram os resultados de seu trabalho. 
Como resultado desse trabalho, observamos no Apêndice do Relatório exemplos que demonstram o quanto uma pedagogia não autoritária, mediada pelo conhecimento psicanalítico, contribui para o desenvolvimento da autonomia de cada criança, e consequentemente, de todo o grupo.

Uma vez que a criança de tenra idade não consegue apreender o significado de elogios ou repreensôes, se a mesma cometia uma ação ruim, não era reprovada, mas levada a perceber as consequencias dos próprios atos para si e para o restante do grupo. Um dos exemplos, contido na seção 2 do Apêndice do Relatório, é bastante ilustrativo.

Volik, de 3 anos e 3 meses, encontra uma flor de morangueiro. Ele a observa e diz que não se pode arrancá-la, pois mais tarde haverá um morango ali. Genja, 2 anos e Io meses, corre e arranca-a. Volik fica muito infeliz e diz: "Ele arrancou a florzinha, agora não crescerá morango". Outra criança, Hedy, de 3 anos e 5 meses, se aproxima e pergunta: "Mas Genja, o que você fez? Por que arrancou a florzinha? Genja, sem hesitar: "[Porque] Eu quis". Hedy então pergunta: "mas você não quer comer morango?" Genja cala-se, e embaraçado diz baixinho: "Claro que eu quero". Hedy, entâo, retruca: "Mas agora já não há morango". Genja volta ao local, apanha a flor do chão e a repóe no pé. As crianças riem alegremente e Volik diz à educadora: "Genja repos e flor, agora vai haver morango outra vez". A educadora nada disse para não desiludi-lo.

\section{0 fim de uma experiência pioneira}

Com poucos meses de existência, a Casa das Crianças começou a ter problemas para a sua manutenção. Pessoas cujos padrôes educacionais tinham por base a coerção e os castigos físicos, não viam com bons olhos o trabalho escolar de Vera Schmidt. Tal experiência inovadora gerou desconfianças e rumores sobre o que se passava, de fato, dentro do jardim de infância. Prenúncios de censura ideologica já podiam ser sentidos.

Nesse cenário, foi constituída uma comissão composta por um pediatra, um pedagogo, um psicólogo e um representante do Comissariado do Povo para Instrução Pública para avaliar o trabalho desenvolvido na Casa das Crianças de Moscou. O psicólogo criticou severamente o trabalho, e embora os demais profissionais se posicionassem favoravelmente, o jardim de infância perdeu uma de suas fontes de financiamento. Pouco tempo depois, a direção do Instituto de Neuropsicologia de Moscou passou às mãos de um ferrenho adversário da Psicanálise, ao qual Vera Schmidt se refere apenas como Prof. N. Em suas palavras, o Prof. N. "insultou o diretor, a equipe e até mesmo as crianças do Jardim de Infância Experimental” (Schmidt, I924, p. 4; 1975, p. I6). Depois disso, o Instituto de Neuropsicologia náo apenas suspendeu a outra parte do financiamento, como também se empenhou consideravelmente em sua condenação ideológica.

Porém, no mesmo dia em que a Casa das Crianças de Moscou deveria fechar suas portas, a Confederação Alemã e Russa de Mineiros tomou para si a responsabilidade financeira de manutenção da instituição. A partir de abril de 1922, a escola passou a se chamar "Solidariedade Internacional". No outono desse mesmo ano foi fundado o Instituto Estatal de Psicanálise, e o jardim de infância ficou formalmente vinculado a ele. 
Entretanto, após a morte de Lênin, e com recursos cada vez mais escassos, em I4 de agosto de 1925 o Ministério da Educação Pública decretou o encerramento definitivo da Casa das Crianças de Moscou.

A Vera Schmidt restou renunciar ao seu trabalho como educadora e se tornar pesquisadora no Centro de Estudos do Sistema Nervoso, anexo à Academia de Ciências, onde permaneceu até 1929. Nesse mesmo ano, Trotsky, simpático ao movimento psicanalítico, foi exilado, e Wilhelm Reich esteve na Uniáo Soviética. Interessado pelo relato da experiência educacional de Vera Schmidt, Reich visitou algumas instituiçôes soviéticas de educação infantil. ${ }^{13}$ Constatou que, embora muitas atividades fossem avançadas para os padrôes burgueses, inclusive com a abolição do ensino religioso, as manifestaçóes da sexualidade infantil eram ignoradas ou reprimidas com a mesma frequência com que o faziam os defensores da moral e dos bons costumes. Em artigo sobre essas visitas, observa em relação à educaçáo das crianças:

Podem dar-se duas possibilidades: I) doutrinar as crianças nos ideais revolucionários em lugar dos ideias burgueses patriarcais; 2) renunciar ao doutrinamento ideológico substituindo-o pela formaçấo de uma estrutura infantil que leva a criança a reagir espontaneamente de um ponto de vista coletivo e comunista e que a leve a aceitar a atmosfera revolucionária sem revolta (subjacente). O segundo método está de acordo com o princípio de autonomia desejado, o primeiro não (Reich, 1929, p. 42).

Como observam Bittar e Ferreira Jr. (2015, p. 453), "a partir de 1930, com o recrudescimento político imposto por Stalin, o ativismo pedagógico foi condenado, e o trabalho nas escolas, limitado".

Entre 1930 e 1937 Vera Schmidt realizou pesquisas sobre doenças inatas do sistema nervoso em crianças pequenas no Centro Experimental de Patologia Cerebral. Durante esse periodo ficou gravemente doente devido a um tumor de tireóide. Ainda participou da expedição polar "Tchelouskine" organizada por seu marido, embora tal viagem pareça ter contribuído para apressar o seu desaparecimento, em I7 de julho de 1937. Há controvérsias entre autores sobre a causa que determinou sua morte. No Dicionário de Psicanálise de Roudinesco e Plon os autores afirmam que Vera Schmidt "morreu de pneumonia" (Roudinesco e Plon, 1998, p. 690), enquanto o Dicionário Internacional de Psicanálise (Mason, 2005, p. 1544) afirma que ela faleceu na mesa de cirurgia.

Tal desencontro de informaçôes é compreensível, dada a dificuldade de acesso à fontes do periodo pesquisado.

Em 1930 a Sociedade Psicanalítica Russa foi dissolvida, e até 1936 a repressão stalinista ao movimento psicanalítico baniu oficialmente a psicanálise da União Soviética, que foi considerada ciência burguesa. Como consequência, Freud foi banido de livrarias e bibliotecas.

I3 No intuito de promover a participação ativa das mulheres na produção e na vida pública em geral, o Estado Soviético estabeleceu várias creches e jardins de infância, onde a mulher deixaria seu filho durante sua jornada de trabalho. Esse direito foi legalmente assegurado pela Constituição Soviética de 1936, Artigo I22, Capítulo x. 


\section{A retomada da psicanálise}

Como dissemos no início, a Rússia pareceu assimilar a noção de inconsciente bem antes do que os demais países ocidentais, e apesar da proibição oficial da psicanálise, o interesse pelo inconsciente sobreviveu.

Em 1979, os discípulos de um psicólogo da Geórgia, professor e fundador da Universidade Nacional de Tbilisi, Dmitri Uznadze (I886-I950), organizaram o Simpósio Internacional sobre o Inconsciente, em Tbilisi. Muitos estudiosos, médicos, psicólogos, filosóficos e sociólogos, se interessaram não somente pelo estudo do inconsciente, mas pelo estudo da psicanálise, que começou a ser retomada na clandestinidade devido as suas implicaçôes ideológicas. ${ }^{14}$

A partir da década de 1980, as ideias psicanalíticas começam a ser publicadas novamente na imprensa científica e a se espalhar na sociedade. Um exemplo é Sergey Agrachev (1952-I998), um dos primeiros russos a fazer análise na clandestinidade a partir de 1977. Engenheiro elétrico, Agrachev presidiu a nova Sociedade Psicanalítica de Moscou ${ }^{15}$ desde o final da uRss até a sua morte em 1998.

Em entrevista ao jornal norte-americano The New York Times, em dezembro de I996, Agrachev conta que atendia vinte pacientes, dois dos quais em "análise profunda" - o que implica quatro sessóes por semana no divã.

O custo médio de uma análise na Rússia na metade dos anos 90 era cerca de US\$20 por hora. Mas o Sr. Agrachev estabelecia o valor da sessão de acordo com a capacidade de pagamento de seus pacientes, e uma sessão variava entre us\$ 8 e uS\$ 65 .

Em julho de 1996, o presidente Boris N. Yeltsin assinou um decreto reconhecendo oficialmente a psicanálise como um tratamento legítimo, o que a levou a ser incorporada ao currículo dos cursos de Psicologia e até a ser ensinada na Universidade Militar do Ministério da Defesa da Federaçáo Russa.

Curiosamente, quando a psicanálise foi retomada, os russos não haviam tido contato com autores pós-freudianos. Nesse sentido, o Sr. Agrachev disse, na mesma entrevista (Stanley, I996, p. 6), que os russos eram "como os mamutes que são descobertos intactos e congelados no permafrost". ${ }^{16}$

No entanto, essa situação já mudou. Os psicanalistas não precisam mais tratar pacientes escondidos em becos, já existem junguianos e lacanianos na Rússia, Winnicott também é estudado, e os círculos freudianos estão sofrendo as rivalidades típicas das instituiçôes ocidentais. Existe um próspero instituto psicanalítico em São Petersburgo e pelo menos três em Moscou, dois dos quais se auto-denominam "Associaçáo Psicanalítica Russa”.

I4 De acordo com Kadyrov (2002/20I8, p. I), embora as obras de Freud tenham sido retiradas de circulaçáo pública, nos anos 70 e 80 era possível obter fotocópias das obras de Freud publicadas nos anos 20 na biblioteca do Departamento de Psicologia da Universidade de Moscou.

I5 A Sociedade Psicanalítica de Moscou foi criada em 1988, inicialmente como uma divisão da Associação de Psicólogos Clínicos. A Divisão de Psicanálise se tornou Sociedade Psicanalítica de Moscou em i995 (Alavidze e Arutyunyan, 2016, p. I0).

I6 Termo utilizado em Geografia para caracterizar um tipo de solo encoantrado na região do Ártico. 
Como disse o Dr. Aron I. Belkin, fundador de uma dessas duas escolas rivais e famoso na Rússia por ter publicado um artigo de jornal exaltando a psicanálise em I988, quando Freud ainda era oficialmente tabu: "Não podemos copiar o Ocidente", disse ele, "Nós somos diferentes. Precisamos desenvolver uma psicanálise puramente russa para nos entender" (Stanley, 1996, p. 6).

\section{Referências bibliográficas}

Accerboni, Anna Maria (2005). "Rosenthal, Tatiana". In: Mujolla, A. de (Org.). International Dictionary of Psychoanalysis. Thomson Gale: Detroit, p. 1515.

Alavidze, Tatiana; Arutyunyan, Marina (20I6). "Meet the Moscow Psychoanalytic Society" [online]. 24 de dezembro de 20I6. Disponível na internet via: http://www.psychoanalysismps.ru [Consultado em 03.10.2017]

Brenner, Frank (1999). "Intrepid thought: psychoanalysis in the Soviet Union". [online]. In: World Socialist Web Site. Disponível na internet via: https://www.wsws.org/en/articles/1999/o6/freu-jir.html [Consultado em em 03.IO.2017]

Bittar, Marisa; Ferreira Jr., Amarílio (2011). "A Educação na Rússia Soviética”. Revista HISTEDBR, Campinas, número especial, pp. 377-396.

(20I5). "Ativismo pedagógico e princípios da escola do trabalho nos primeiros tempos da educação soviética”. Revista Brasileira de Educação, v. 20, n. 6I.

COMitê Central dos Jardins de infÂncia socialistas de berlim; Reich, Wilhelm; Schmidt, Vera (1975). "Elementos para uma pedagogia anti-autoritária”. Porto, Portugal: Publicações Escorpião.

Etkind, Alexander M. (1995). "Russia by Alexander M. Etkind: The Reception of Psychoanalysis in Russia until the Perestroika”. Disponível na internet via: https://web.archive.org/ web/2007030512305I/http://psychoanalyse.narod.ru/english/ruetkind.htm [Consultado em em I0.03.2018]

Freud, Sigmund (1918-1919). "Caminhos da Terapia Psicanalítica”. Buenos Aires: Amorrortu Editores, vol. 17, pp. I5I-163, I992.

Kadyrov, Igor M. (2002). "The Future of Psychoanalysis in Europe. East-West Integration”. Disponível na internet via: http://www.psihoanalitiki-ipa.si/files/Kadyrov-Future.pdf [Consultado em em 10.03.2018]

Lenin, V. I. (200I [1920]). "As tarefas das Uniōes da Juventude" (Discurso pronunciado no III Congresso de toda a Rússia da União Comunista da Juventude da Rússia em 2 outubro de 1920). Revista HISTEDBR, Campinas, número especial, pp. 367-376.

Mason, Irina (2005). "Schmidt, Vera Federovna (I889-I937)". In: Mijolla, A. de (Org.). International Dictionary of Psychoanalysis. Thomson Gale: Detroit, pp. I543-I544.

Mijolla, Alain de (2005). (Org). "International Dictionary of Psychoanalysis". Thomson Gale: Detroit.

NOVA CONSTITUIÇÃo SOviÉTiCA - I936 [online]. Disponível na internet em 04.04.20II via: https://www.marxists.org/portugues/stalin/biografia/ludwig/constituicao.htm.

Nölleke, Brigitte (2017). "Psychoanalytikerinnen. Biografisches Lexikon" [online]. Disponível na internet via: https://www.psychoanalytikerinnen.de/russland_biografien.html [Consultado em 06.03.2018] 
ReIch, Wilhelm (1975). “Os Jardins de Infância na Rússia Soviética (I929)”. In: Elementos para uma pedagogia anti-autoritária, pp. 39-52. Porto, Portugal: Publicaçôes Escorpião.

Roudinesco, Elisabeth; Plon, Michel (1998). Dicionário de psicanálise. Rio de Janeiro: Zahar Editores.

Schmidt, Vera (1924). "Psychoanalytische Erziehung in Sowjetrussland. Bericht über das Kinderheim-Laboratorium in Moskau". Internationaler Psychoanalytischer Verlag: Leipzig/ Wien/Zürich.

(1975). "Educação Psicanalítica na Rússia Soviética". In: Elementos para uma pedagogia anti-autoritária. Porto, Portugal: Publicaçóes Escorpião, pp. 15-38.

Stanley, Alessandra (1996). "Freud in Russia: Return of Repressed". In: New York Times, II de dezembro de 1996. [online]. Disponível na internet desde 2017 via: http://www.nytimes. com/1996/r2/II/world/freud-in-russia-return-of-the-repressed.html.

Trotsky, Leon (2005). "Revolutionary and Socialist Art". In: Literature and Revolution. I925. Chicago, Illinois: Haymarket Books, 2005.

UNESCO - International Bureau of Education (1994). "Prospects: the quarterly review of comparative education". Paris: UNESCO - International Bureau of Education, vol. 24, n. 3/4, I994, pp. 687-70I.

Van der Veer, René (20II). "Tatyana on the Coach: the Vicissitudes of Psychoanalysis in Russia”. In: Salvatore, Sergio; Zittoun, Tania (Org.). Cultural Psychology and Psychoanalysis: Pathways to Synthesis, pp. 49-65. IAP: Charlotte, EUA.

Vasilyeva, Nina (2000). "Psychoanalysis in Russia: The Past, the Present, and the Future". American Imago, v. 57, n. I, pp. 5-24.

Vygotsky, Lev; Luria, Alexander (1925). "Introduction to the Russian translation of Freud's Beyond the pleasure principle". Lev Vygotsky, Alexander Luria. Disponível na internet via: https://www.marxists.org/archive/vygotsky/works/reader/poio.pdf [Consultado em 06.03.2018] 